\title{
МЕЖДУНАРОДНО-ПРАВОВЫЕ ГАРАНТИИ ПРАВ ЛИЦ С ПСИХИЧЕСКИМИ РАССТРОЙСТВАМИ
}

\begin{abstract}
Аннотация. В статье дается обзор основных международно-правовых документов, принятых на уровне ООН, а также Советом Европь, и посвященных гарантиям прав лии с психическими расстройствами. Психические расстройства затрагивают миллионы людей во всем мире. По оценкам Всемирной Организации Здравоохранения (ВОЗ) такие расстройства в 2004 г. составляли 13\% глобального бремени болезней. При этом лица, страдающие психическими расстройствами, нередко подвергаются дискриминачии, их права нарушаются, а оказываемая им психиатрическая и социальная помощь не всегда соответствует современным стандартам. Эти обстоятельства обусловливают внимание к правам таких лич на международном уровне. Все международно-правовые документы в области прав человека могут быть разделены на две категории - юридически обязательные для государства, ратифицировавщего подобный международный акт, и так называемые «международные стандарты прав человека», представляюшие собой директивы, руководящие указания и содержащиеся в международных декларациях, резолюииях или рекомендациях, принимаемых, как правило, международными организациями. По сфере применения международно-правовые инструменты в области прав человека являются универсальныли и региональными. К первым относятся международно-правовые акты, принятые, прежде всего, Организацией Объединенных Наций и специализированными учреждениями ООН (например, ВОЗ), вторые исходят от международных организаџий регионального уровня. Кроме того, действующий на основании Конвениии о защите прав человека и основных свобод Европейский суд по правам человека, вынося решения по конкретным делам, касающимся прав лии с психическими расстройствами, создает прецедентное право в этой области, которое наряду с международно-правовыми актами, может использоваться при подготовке или пересмотре национальных законов в сфере психического здоровья, а также практики их применения. Ключевые слова: психчческое здоровье, психическое расстройства, права человека, психиатрическая помощь, международное право, международно-правовые документы, психические заболевания, Конвенция, Европейский суд, улучшения здравоохранения
\end{abstract}

Abstract: The article contains an overview of the main international legal documents of the UN and the Council of Europe concerning the guarantees of rights of persons suffering from the mental disorders. Millions of people around the world suffer from mental disorders. In accordance with the evaluation provided by the World Health Organization (WHO) by 200413 per cent of all illnesses were mental disorders. At the same time the persons suffering from mental disorders are often discriminated and their rights are violated, while the social and psychiatric aid to them often fails to meet the modern standards. These circumstances substantiate the interest towards the rights of such persons at the international level. All of the international legal documents in the sphere of human rights may be divided into two categories: those legally binding for the states, which have ratified such an international legal act and the so-called international human rights standards, serving as directives, and guidelines, which may be found in international declarations, resolutions and recommendations, and such acts are mostly adopted by the international organizations. In accordance to the sphere of their application international legal instruments in the sphere of human rights may be divided into universal and regional ones. The former include international legal acts of the UN and its specialized institutions, such as the WHO, and the latter ones are initiated by the regional international organizations. Additionally, the European Court of Human Rights, acting based upon the Convention for the Protection of Human Rights and Fundamental Freedoms, makes decisions on specific cases regarding rights of persons suffering from mental disorder, and, therefore, it forms precedents in this sphere. These precedents may be used together with the international legal acts in order to draft or amend national laws in the sphere of mental health and practice of their application.

Keywords: mental health, mental disorder, human rights, psychiatric aid, international law, international legal documents, mental illnesses, the Convention, the European Court of Human Rights, health care improvement. 
сихические расстройства затрагивают миллионы людей во всем мире. По оценкам Всемирной Организации Здравоохранения (BO3) такие расстройства в 2004 г. составляли $13 \%$ глобального бремени болезней ${ }^{1}$. Только в странах Европейского Союза ежегодно более трети населения страдают от различных расстройств психики, что в 2011 г. составляло 164, 8 млн. человек ${ }^{2}$.

Лица, страдающие психическими расстройствами, нередко подвергаются дискриминации, их права нарушаются, а оказываемая им психиатрическая и социальная помощь не всегда соответствует современным стандартам. К примеру, по данным BO3, от 76 до 85\% лиц с тяжелыми психическими расстройствами не получают необходимого лечения в странах с низкими и средними доходами. Для сравнения в странах с высокими доходами число таких больных колеблется от 35 до $50 \%{ }^{3}$.

Эти обстоятельства обусловливают особое внимание к обеспечению и защите прав лиц с психическими расстройствами и обращение в этой связи к международному праву прав человека ${ }^{4}$. В контексте психического здоровья, как отмечают Л.Гостин и Л.Гейбл, международное право в области прав человека является важным « вследствие двух фундаментальных идей, уникальных для глобальной защиты прав и свобод. Во-первых, право прав человека является единственным правовым источником, легитимирующим международную проверку политики и практики в сфере психического здоровья в суверенной стране. Во-вторых, международное право прав человека обеспечивает фундаментальную

\footnotetext{
${ }^{1}$ Resolution WHA65.4. (здесь и далее источник для резолюций и документов BO3: WHO MiNDbank // URL: www.who.int/ mental_health/mindbank) (дата обращения - 22 ноября 2013 г.).

${ }^{2}$ Wittchen H.U. et al. The size and burden of mental disorders and other disorders of the brain in Europe 2010 //European Neuropsychopharmacology (2011) 21. P.656//www.elsevier. com/locate/euroneuro.

${ }^{3}$ См.: Comprehensive mental health action plan 2013-2020. Para.14 // Resolution WHA66.8. Document A66/10 Rev.1 - 16 May 2013.

${ }^{4} \mathrm{O}$ терминологии см.: Международное публичное право: учеб. /Л.П. Ануфриева, Д.К. Бекяшев, К.А. Бекяшев [и др.]; отв. ред. К.А.Бекяшев. - М.: ТК Велби, Изд-во Проспект, 2004. C. 270 .
}

защиту, которую нельзя отнять обычным политическим путем» ${ }^{5}$.

Все международно-правовые документы в области прав человека могут быть разделены на две категории - юридически обязательные для государства, ратифицировавшего подобный международный акт, и так называемые «международные стандарты прав человека», представляющие собой директивы, руководящие указания и содержащиеся в международных декларациях, резолюциях или рекомендациях, принимаемых, как правило, международными организациями. Конечно, рекомендации не обладают обязательной юридической силой, но «могут быть весьма жесткими в политическом смысле и представляют собой бесспорное средство оказания политического давления» ${ }^{6}$. В рекомендациях отражается мнение большинства членов международной организации, и можно сказать, что в них речь идет об общих принципах, которые в дальнейшем могут трансформироваться в международный обычай или даже норму договора. Примером трансформации положений «мягкого» международного права в юридически обязательные предписания может служить Всеобщая декларация прав человека 1948 г., которая не мыслилась как юридически обязательный документ, а рассматривалась лишь «как первый шаг в деле подготовки пакта, который будет иметь форму международного договора» ${ }^{7}$. В дальнейшем положения Декларации вошли в принятые ООН 19 декабря 1966 г. Международный пакт о гражданских и политических правах и Международный пакт об экономических и социальных правах.

По сфере применения международно-правовые инструменты в области прав человека являются универсальными и региональными. К первым относятся международно-правовые акты, принятые, прежде всего, Организацией Объединенных Наций и специализированными учреждениями ОOH (например, ВО3), вторые исходят от международных

\footnotetext{
${ }^{5}$ Gostin L., Gable L. The Human Rights of Persons with Mental Disabilities: a Global Perspective on the Application of Human Rights Principles to Mental Health// Maryland Law Review. 2004. Vol.63:20. P. 21.

${ }^{6}$ Нгуен Куок Динь, Дайе П., Пеле А. Международное публичное право: в 2-х т. - Киев: «Сфера», 2000. Т.1. С.223.

${ }^{7}$ Броунли Я. Международное право: в 2-х кн. - М.: «Прогресс», 1977. Кн. 1. С.268.
} 
организаций регионального уровня ${ }^{8}$. В региональных системах защиты прав человека «применяется дополнительная защита прав человека в соответствующем географическом регионе. Как международная, так и региональная системы обращаются к правам человека для лиц с психической неполноценностью с помощью договоров, деклараций и тематических резолюций»9.

Так, два Пакта и Факультативный протокол к Международному пакту о гражданских и политических правах рассматривают как «детальную кодификацию прав человека» ${ }^{10}$. Современная международная и национальная политика в сфере психического здоровья должна строиться в первую очередь в соответствии с положениями этих документов ${ }^{11}$. Также должны использоваться специализированные конвенции $\mathrm{OOH}$, в частности, Конвенция о правах инвалидов от 13 декабря 2006 г. $^{12}$.

Среди рекомендательных документов, прямо относящихся к лицам, страдающим психическими расстройствами, особое место занимают Принципы защиты лиц, страдающих психическим заболеванием, и улучшения здравоохранения в области психиатрии, принятые Генеральной Ассамблеей ООН 17 декабря 1991 г. (далее - Принципы ООН) ${ }^{13}$.

На сегодняшний день Принципы ООН содержат самый полный набор требований к обеспечению прав лиц, страдающих психическими расстройствами. Этот документ стал итогом работы, начатой в конце 70-ых г.г. прошлого века Комиссией $\mathrm{OOH}$ по правам человека и Подкомиссией по предотвращению дискриминации и защите меньшинств. В результате были сформулированы 25 принципов, касающихся лиц с психическими расстройствами.

Именно широта содержания Принципов $\mathrm{OOH}$ придает этому документу, несмотря на его реко-

\footnotetext{
${ }^{8}$ Обзор основных международных универсальных и региональных документов в области прав человека, касающихся лиц с психическими расстройствами, см.: WHO Resource Book on Mental Health, Human Rights and Legislation. World Health Organization, 2005. P.9-16.

${ }^{9}$ Gostin L., Gable L. Op.cit. P.23.

${ }^{10}$ Броунли Я. Указ. соч. С.268.

${ }^{11}$ См., например: Comprehensive mental health action plan 2013-2020.

12 Ратифицирована Российской Федерацией. - Федеральный закон от 03.05.2012 N 46-Ф3. - СЗ РФ. 2013. N 6. Ст. 468

${ }^{13} \mathrm{~A} / \mathrm{RES} / 46 / 119$.
}

мендательный характер, исключительное значение. Так, Принципы ООН являются, по выражению Д.Гостина и Д.Гейбла, «полезным руководством по толкованию» универсальных и региональных конвенций о правах человека применительно к лицам с психическими расстройствами ${ }^{14}$.

Далее, содержание международных принципов «обеспечивает государства стандартом для оценки своего собственного уровня соответствия международным нормам прав человека в отношении лиц с психической неполноценностью» ${ }^{15}$.

Кроме того, Принципы ООН как «минимальные стандарты прав человека в практике в сфере психического здоровья» ${ }^{16}$ влияют на содержание национальных законов, касающихся лиц с психическими расстройствами, в том числе регламентирующих оказание психиатрической помощи. Многие страны, среди которых - Австралия, Венгрия, Мексика и Португалия, полностью или частично инкорпорировали положения этого документа в национальное законодательство ${ }^{17}$. Учтены Принципы ООН и в российском Законе «О психиатрической помощи и гарантиях прав граждан при ее оказании» от 2 июля 1992 г. ${ }^{18}$

В соответствии с Принципами ООН лица, страдающие психическими расстройствами, подлежат защите от дискриминации, под которой понимаются «любые разграничения, недопущение или предпочтение, сводящее на нет или нарушающее равенство использования прав (п.4 принципа 1). При этом дискриминацией не считаются специальные меры, предназначенные исключительно для защиты или развития прав таких лиц, а также «любые разграничения, недопущение или предпочтение, предпринятые в соответствии с настоящими Принципами и необходимые для защиты прав человека в отношении лица, страдающего психическим заболеванием или иных лиц».

\footnotetext{
${ }^{14}$ Gostin L., Gable L. Op.cit. P. 38.

${ }^{15}$ Idid. P.43.

${ }^{16}$ WHO Resource Book on Mental Health, Human Rights and Legislation. P. 13.

${ }^{17}$ Ibid. Р.14. Подробнее о влиянии Принципов ООН на законодательство о психическом здоровье в Австралии см.: Zifcak $S$. The United Nation Principles for the Protection of People with Mental Illness: Applications and Limitations// Psychiatry, Psychology and Law. Vol.3. Number 1. April 1996. P.1-9.

18 Ведомости Съезда народных депутатов и Верховного Совета РФ. - 1992. - № 33. - Ст. 1913.
} 
Принципы ООН содержат перечень прав, которые должны быть обеспечены лицам с психическими расстройствами и могут быть разделены на три группы. В первую группу входят гражданские и политические права, которыми пользуются все граждане государства, независимо от состояния их психического здоровья. Вторая группа прав специально выделяется для рассматриваемой категории граждан, поскольку лица с психическими расстройствами нередко страдают от дискриминации, плохого обращения и нарушений их прав и в обычной жизни, и при оказании психиатрической помощи. Третью группу прав составляют права пациентов психиатрических учреждений. Такие учреждения нередко являются закрытыми и потому требуют особого внимания с точки зрения обеспечения прав человека.

Предлагаемая классификация прав лиц с психическими расстройствами отражена и в Принципах ООН. К примеру, в п.5 принципа 1 подтверждается, что «любое психически больное лицо имеет право на осуществление всех гражданских, политических, экономических, социальных и культурных прав, признанных во Всеобщей декларации прав человека, Международном пакте об экономических, социальных и культурных правах, Международном пакте о гражданских и политических правах и в других соответствующих документах, таких как Декларация о правах инвалидов и Свод принципов защиты всех лиц, подвергаемых задержанию или заключению в какой бы то ни было форме».

Далее подробно раскрываются права лиц с психическими расстройствами, которыми они должны пользоваться как уязвимая группа населения. На первое место поставлено право на наилучшую имеющуюся психиатрическую помощь как часть общей системы медицинской и социальной помощи (п.1 принципа 1). К этой же группе прав относится право на гуманное и уважающее их человеческое достоинство отношение (п.2 принципа 1), защиту от экономической, сексуальной и иных форм эксплуатации, физических и иных злоупотреблений (п.3 принципа 1), а также права проживать и работать, по возможности, в обществе (принцип 3), на помощь адвоката и личного представителя (принцип 18), на подачу жалоб в порядке, установленном внутренним законодательством (принцип 21).

В Принципах ООН также формулируются стандарты, которые должны соблюдаться при любых контактах лиц с психическими расстройствами и медицинских работников. Так, установление психиатрического диагноза должно осуществляться в соответствии с общепринятыми международными медицинскими стандартами. Диагноз психического расстройства не может основываться на каких-либо иных обстоятельствах, кроме состояния психического здоровья лица в момент постановки диагноза. При этом сведения о лечении или госпитализации в качестве пациента в прошлом не могут сами по себе служить оправданием постановки диагноза о наличии психического заболевания в настоящем или будущем (принцип 4). Медицинское обследование не должно проводиться в нарушение порядка, установленного национальным законодательством (принцип 5). Те пациенты, которым поставлены психиатрические диагнозы, имеют право на медицинскую и социальную помощь по возможности по месту жительства (принцип 7) в соответствии с теми же стандартами, которым применяются к больным с иными медицинскими диагнозами (принцип 8), в наименее ограничительных условиях и с применением наименее ограничительных видов лечения (принцип 9).

Чрезвычайно важным являются положения принципа 11, в соответствии с которым никакое лечение не может назначаться пациенту без его осознанного согласия. Осознанное согласие - это согласие, получаемое свободно, без угроз или неоправданного принуждения после надлежащего предоставления пациенту в форме и на языке, понятном ему, достаточной и ясной информации о предварительном диагнозе; цели, методах, вероятной продолжительности и ожидаемых результатах предлагаемого лечения; альтернативных методах лечения, включая менее инвазивные; а также возможных болевых ощущениях и ощущениях дискомфорта, возможном риске и побочных эффектах предлагаемого лечения. При этом пациент имеет право отказаться от лечения или прекратить его, за исключением случаев законного применения недобровольного лечения. Такому пациенту должны быть объяснены последствия отказа от лечения или его прекращения.

По общему правилу лечение без согласия пациента возможно, если он госпитализирован в недобровольном порядке, независимый полномочный орган, располагающий всей соответствующей информацией, «удостоверился в том, что в данный момент пациент не в состоянии дать или не 
дать осознанное согласие на предлагаемый курс лечения или, если это предусмотрено внутригосударственным законодательством, в том, что с учетом собственной безопасности пациента или безопасности других лиц пациент необоснованно отказался дать такое согласие», и кроме того «независимый полномочный орган установил, что предлагаемый курс лечения наилучшим образом отвечает интересам здоровья пациента» (п.6). Допускается также лечение с согласия личного представителя пациента (п.7) и по решению «квалифицированного специалиста» в неотложных случаях (п.8). В тех случаях, когда какое-либо лечение назначается пациенту без его осознанного согласия, следует прилагать все усилия к тому, чтобы информировать пациента о характере лечения и о любых возможных альтернативных методах, а также, насколько это возможно, привлекать его к разработке курса лечения. Любое назначенное лечение должно регистрироваться в истории болезни пациента с указанием того, является ли оно принудительным или добровольным.

В этом же принципе содержатся ограничения на применение медицинских средств и методов $($ п.12, 14), проведение клинических исследований и использование экспериментальных методов лечения (п.15).

Порядок госпитализации в психиатрический стационар, включая содержательные и процедурные основания для ее проведения в недобровольном порядке, содержатся в принципах 15 и 16. Каждый случай недобровольной госпитализации должен рассматриваться судебным или иным независимым и беспристрастным органом, установленным и действующим в соответствии с национальным законодательством, которому также предоставлено право периодического пересмотра дел недобровольно госпитализированных пациентов «с разумным интервалом времени» (принцип 17). В этой связи психиатрические пациенты имеют право на определенные процедурные гарантии, чтобы рассмотрение их дел в контрольном органе было на самом деле всесторонним, а решение этого органа - в полной мере обоснованным (принцип 18). Среди таких гарантии - права на выбор адвоката для представления своих интересов, включая представительство в ходе любой процедуры рассмотрения жалобы или апелляции и на услуги переводчика при такой необходимости. Пациент, его представитель и адвокат имеют право присутствовать на любом слушании, участвовать в нем и быть заслушанными.

Помимо предписаний, касающихся прав лиц с психическими расстройствами, Принципы ООН имеют значение и для организации национальных служб, оказывающих психиатрическую и социальную помощь таким лицам. К примеру, положения принципов 3 и 7 о праве каждого лица, страдающего психическим расстройством, в той степени, в какой это возможно, проживать и работать в обществе и получать психиатрическую помощь по месту жительства требуют соответствующей организации медицинской и социальной помощи в конкретном государстве. Кроме того, в принципах 1, 8 и 14 подчеркивается, что психиатрическая помощь является частью национальной системы здравоохранения и социальной помощи, работающей по одинаковым стандартам с другими видами медицины, и психиатрическим учреждениям «должен быть доступен тот же уровень ресурсов, что и для любых других учреждений здравоохранения». Это означает, что государствам рекомендуется так распределять финансовые и материальные ресурсы, чтобы психиатрия финансировалась в том же объеме, как иные области здравоохранения. Наконец, направленность психиатрического лечения на сохранение и развитие личной автономии пациента (п.4 принципа 9) и право пациентов на скорое возвращение к жизни в обществе после лечения в психиатрическом учреждении (п.2 принципа 7) создают основу для идеологии современной психиатрии, инкорпорирующей уважение к автономии, правам и достоинству пациентов в каждодневную практику.

В дальнейшем $\mathrm{BO} 3$ разработала ряд инструментов, разъясняющих положения Принципов $\mathrm{OOH}$ и облегчающих их практическое применение. К таким документам относится «Инструкция по содействию реализации прав человека для лиц, страдающих психическими расстройствами» ${ }^{19}$ и «Закон о психиатрической помощи: десять основных принципов» ${ }^{20}$.

Инструкция была составлена для содержательной оценки условий, связанных с реализацией каждого из принципов, и потому относится «К вопросу основных гарантий качества, устанавливая таким образом тот базовый уровень, с которого полити-

\footnotetext{
${ }^{19} \mathrm{WHO} / \mathrm{MNH} / \mathrm{MND} / 95.4$.

${ }^{20} \mathrm{WHO} / \mathrm{MNH} / \mathrm{MND} / 96.9$.
} 
ки и психиатрические работники могут оценивать программы психического здоровья местного, регионального и национального уровней» ${ }^{21}$. Задачей второго документа являлось описание базовых принципов «для области психического здоровья при минимально возможном включении факторов отдельной культуры или правовых традиций»22. Эти инструменты ВОЗ мыслились как справочные при оценке степени защищенности прав лиц с психическими расстройствами, а также и состояния психиатрической службы с конкретной стране.

В продолжение этой работы в 2001 г. был опубликован специальный документ ВО3, посвященный роли международно-правовых актов в области прав человека в защите прав лиц, страдающих психическими расстройствами, призванный оказать помощь национальным законодателям в разработке законов в сфере психического здоровья ${ }^{23}$. Но самым полным и потому наиболее информативным стала Справочное пособие по психическому здоровью, правам человека и законодательству ${ }^{24}$. В подготовке пособия участвовали представители многих стран как психиатры, так и юристы. Главы и приложения этой книги содержат многочисленные примеры разнообразной практики в названной области, а также выдержки от национальных законов и других правовых документов разных стран.

Кроме защиты прав лиц с психическими расстройствами на уровне международного сообщества в целом, внимание этим вопросам уделяется и на региональном уровне. Среди региональных документов общего характера необходимо указать европейскую Конвенцию о защите прав человека и основных свобод от 4 ноября 1950 г. ${ }^{25}$ и Европейскую социальную хартию от 18 октября 1961 г.

Европейская конвенция предусматривает развитые механизмы защиты прав человека, главным из

\footnotetext{
${ }^{21}$ Инструкция по содействию реализации прав человека для лиц, страдающих психическими расстройствами. - Киев: «Сфера», 1997. С.10.

22 Закон о психиатрической помощи: десять основных принципов. - Киев: «Сфера», 1997. С.6.

${ }^{23}$ The Role of International Human Rights in National Mental Health Legislation. - WHO, 2001.

${ }^{24}$ WHO Resource Book on Mental Health, Human Rights and Legislation. - WHO, 2005.

${ }^{25}$ Ратифицирована Российской Федерацией // СЗ РФ. 1998. № 14. Ст.1514; С3 РФ. 1998. № 44. Ст.5400, Официальный перевод на русский язык см.: С3 РФ. 2001. № 2. Ст.163.
}

которых является деятельность Европейского суда по правам человека. Действующий на основании Конвенции Суд выносит решения по конкретным делам, тем самым создавая прецедентное право. При этом «Конвенция и прецедентное право Суда являются не только ориентиром, с помощью которого правительства могут законы применять, а национальные суды могут законы толковать. По существу Конвенция действует как международная ревизия правительственных неумеренностей или, как обычно происходит в области психической неполноценности, небрежности» ${ }^{26}$.

Практика Европейского суда по правам человека показывает, что в отношении лиц с психическими расстройствами чаще других нарушаются такие статьи Европейской конвенции как ст.3 (право на физическую неприкосновенность), ст.5 (право на свободу и личную неприкосновенность), ст.6 (право на справедливое судебное разбирательство) и ст. 8 (право на уважение частной и семейной жизни, жилища и корреспонденции).

Статья 3 Конвенции устанавливает, что «никто не должен подвергаться пыткам и бесчеловечному или унижающему достоинство обращению или наказанию» и защищает человеческое достоинство и физическую неприкосновенность человека. По степени жестокости Европейский суд различает пытку (бесчеловечное обращение, имеющее целью получить какую-либо информацию или признание либо наказать), бесчеловечное обращение или наказание (такое обращение, которое намеренно влечет серьезные моральные или физические страдания и не может быть оправданным в данной ситуации), а также унижающее достоинство обращение или наказание (обращение, которое грубо унижает человека перед другими и принуждает его поступать против своей воли или совести) ${ }^{27}$.

На практике Европейский суд по правам человека весьма осторожно подходит к признанию нарушений статьи 3 Конвенции. Например, в деле Herczegfalvy v. Austria, по которому заявитель - пациент психиатрического учреждения - жаловался

\footnotetext{
${ }^{26}$ Lewis $O$. Protecting the Rights of People with Mental Disabilities: The European Convention on Human Rights//European Journal of Health Law. 2002. Number 9. P. 293.

${ }^{27}$ См.: Гомиен Д. Путеводитель по Европейской конвенции о защите прав человека. - Страсбург: Совет Европы. 1994. C.14-15. См. также: Gostin L., Gable L. Op.cit. P. 80-81.
} 
на то, что его насильно кормят и дают лекарства, что он был изолирован на длительный период времени и фиксирован на специальной кровати с помощью наручников, Суд не признал нарушений статьи 3. Суд счел, что у него нет достаточных доказательств, чтобы опровергнуть утверждение правительства о наличии медицинской необходимости, на тот момент оправдывающей такое обращение. При этом Суд отметил, что состояние неполноценности и беспомощности, типичные для пациентов психиатрических учреждений требует повышенного внимания при рассмотрении вопросов о соблюдении положений Конвенции. В этой связи Суд выразил обеспокоенность длительностью времени, в течение которого применялись наручники и специальная кровать ${ }^{28}$.

Также Суд не признал нарушения статьи 3 по делу Aerts v. Belgium, заявитель по которому - заключенный, помещенный в психиатрическое отделение тюрьмы Лантин - жаловался на отсутствие необходимой психиатрической помощи, что привело к ухудшению его психического здоровья и потому является бесчеловечным и унижающим достоинство обращением. Соглашаясь с тем, что общие условия содержания заключенных в данном тюремном психиатрическом отделении были неудовлетворительными, и заключенным не обеспечивалось эффективное лечение, Суд не установил в этом деле доказательств действительного ухудшения психического здоровья заявителя. В этой связи Суд указал, что условия нахождения в психиатрическом отделении не кажутся имеющими столь серьезные последствия для его психического здоровья, чтобы признать это подпадающим под статью 3 Европейской конвенции ${ }^{29}$.

Статья 5 Европейской конвенции о защите прав человека и основных свобод регламентирует право на свободу и личную неприкосновенность. Это право не является абсолютным и может быть ограничено в случаях, перечисленных в этой же статье, п. «е» которой разрешает «законное задержание лиц с целью предотвращения распространения инфекционных заболеваний, а также душевнобольных, алкоголиков, наркоманов или

\footnotetext{
${ }^{28}$ Herczegfalvy v. Austria. Judgement of September 1992.

${ }^{29}$ Aerts v. Belgium. Judgement 30 July 1998. Описание дела и решение также см.: Human Rights Case Digest. 1998. Vol. IX No. 9. P. 749-754.
}

бродяг». Классическим делом по статье 5 является дело Winterwerp v. The Netherlands ${ }^{30}$. Важность решения по этому делу обусловлена тем, что в нем сформулированы общие критерии в отношении того, что следует понимать под термином «душевнобольные» и каковы минимальные требования к содержательным и процедурным основаниям недобровольной госпитализации.

В решении Европейского суда отмечено, что душевнобольной - «это термин, значение которого постоянно изменяется вместе с развитием исследований в области психиатрии; более гибкими становятся методы лечения, и меняется отношение общества к душевным заболеваниям, при этом в обществе растет понимание проблем душевнобольных. В любом случае п. 1(е) статьи 5, очевидно, не может рассматриваться как разрешение содержания под стражей лица только потому, что его взгляды или поведение не соответствуют нормам, преобладающим в данном обществе» (п.37 решения). Далее, Суд подчеркнул, что «законность» в отношении задержания «предполагает прежде всего соответствие внутреннему праву, а также... цели ограничений, допускаемых статьей 5 п. 1(е)»и «охватывает как процессуальные, так и материально-правовые нормы». В решении отмечается, что «никто не может быть лишен свободы как «лицо, страдающее психическим расстройством», без медицинского заключения, устанавливающего, что его психическое состояние оправдывает обязательную госпитализацию» (п.39 решения).

Используя решение по делу Winterwerp, Европейский суд по правами человека по делу Varbanov v. Bulgaria признал факт нарушения ст.5 Европейской конвенции, поскольку при недобровольной госпитализации заявителя не было достаточных доказательств наличия у него психического расстройства, госпитализация (задержание) не имела правовых оснований по внутреннем законодательстве и действующий на тот момент болгарский Закон о здравоохранении не содержал достаточных гарантий против произвольного применения госпитализации в психиатрический стационар, в

\footnotetext{
${ }^{30}$ Winterwerp v. The Netherlands. Judgement 24 October 1979. Публикация на русском языке: Европейский суд по правам человека: Избранные решения: в 2-х тю М.: «Норма», 2000. T.1. C.288-300.
} 
частности, не требовал медицинского заключения как ее предварительного условия ${ }^{31}$.

Одним из дел, где были признаны нарушения целого ряда статей Европейской конвенции, включая статьи 6 и 8, стало дело Shtukaturov v. Russia ${ }^{32}$. Заявитель был признан недееспособным на основании заявления его матери, которая и была назначена его опекуном. Он не был уведомлен о судебном заседании, и решение, о котором он узнал случайно, было вынесено в его отсутствие. Попытки обжаловать это решение результата не дали по причине отсутствия у заявителя дееспособности. Далее по требованию опекуна Штукатуров был помещение в психиатрическую больницу, при этом он возражал против госпитализации. Во время пребывания в стационаре он подвергался ряду правоограничений, в частности, ему запрещалось встречаться с адвокатом, принимать посетителей, а также не была предоставлена информация о причинах его госпитализации. По этому делу Европейский суд признал нарушения статей 5, 6, 8 и 34 Конвенции, указав, в частности, что заявитель был лишен права на справедливое судебное разбирательство и на уважение его частной жизни ${ }^{33}$.

В то же время Европейский суд не усмотрел нарушения статьи 8 Конвенции в деле Nielsen v. Denmark, в котором тринадцатилетний подросток оспаривал свое помещение в психиатрическое отделение больницы по просьбе своей матери ${ }^{34}$. По мнению Суда, ребенок находился в том возрасте, а на момент госпитализации ему было 12 лет, когда решение принимается его родителями, хотя бы и против желания ребенка, исходя из презумпции, что родители действуют в интересах детей.

\footnotetext{
${ }^{31}$ Varbanov v. Bulgaria. Judgement 5 October 2000. Описание дела и решение также см.: Human Rights Case Digest. 2000. Vol. 11. P. 539-543.

${ }^{32}$ Shtukaturov v. Russia.Judgement 27 March 2008.

${ }^{33}$ Конституционный Суд РФ в постановлении от 27 февраля 2009 г. № 4-П, вынесенном по жалобам граждан Ю.К. Гудковой, П.В. Штукатурова и М.А. Яшиной, признал не соответствующими Конституции РФ ряд статей ГПК РФ и ч.4 ст.28 Закона РФ «О психиатрической помощи и гарантиях прав граждан при ее оказании». - СЗ РФ. 2009. № 11. Ст. 1367. В дальнейшем Федеральным законом от 6 апреля 2011 г. № 67-Ф3 в указанные законы были внесены соответствующие изменения. - С3 РФ. 2011. № 15. Ст.2040.

${ }^{34}$ Nielsen v. Denmark. Judgement 28 November 1988.
}

Приведенные примеры из практики Европейского суда по правам человека представляют собой лишь малую часть решений, затрагивающих права лиц с психическими расстройствами ${ }^{35}$.

Что же касается международно-правовых документов, то наряду с Европейской конвенцией к правам таким лиц непосредственное отношение имеют Европейская конвенция по предупреждению пыток и бесчеловечного или унижающего достоинство обращения или наказания от 26 сентября 1987 г. ${ }^{36}$ и Конвенция о защите прав человека и человеческого достоинства в связи с применением биологии и медицины от 4 апреля 1997 г. ${ }^{37}$ Среди европейских документов необходимо отметить Рекомендации Комитета министров № $\mathrm{R}(83) 2$, касающиеся правовой защиты лиц, страдающих психическими расстройствами, содержащихся как недобровольные пациенты, и Рекомендации 1235(1994) о психиатрии и правах человека, принятые Парламентской Ассамблеей Совета Европы 12 апреля 1994 г.

Первые из названных рекомендаций относятся только к психиатрическим пациентам, госпитализированным в недобровольном порядке, за исключением проходящих принудительное лечение по решению суда в связи с совершенным общественно опасным деянием. Второй документ также обращается в основном к вопросам, возникающим при применении недобровольных психиатрических мер, но при этом указывает, что «пришло время для государств-членов Совета Европы принять правовые меры, гарантирующие уважение прав человека лиц с психическими расстройствами», и призывает Комитет министров принять новые рекомендации в этой области (п.6, 7 Рекомендаций 1235(1994).

Такими документом стали Рекомендации $\operatorname{Rec}(2004) 10$ Комитета министров Совета Европы, касающиеся защиты прав человека и достоинства лиц с психическими расстройствами. Надо отметить, что этот документ также сосредотачивается по преимуществу на гарантиях прав человека при

\footnotetext{
${ }^{35}$ См. к примеру: Summaries of Mental Disability Cases Decided by the European Court of Human Rights. - Mental Disability Advocacy Center. 2007.

${ }^{36}$ Ратифицирована Российской Федерацией - Федеральный закон от 28 марта 1998 г. // СЗ РФ. 1998. № 13. Ст.1466. Официальный перевод Конвенции на русский язык см.: С3 РФ. 1998. № 36. Ст. 4465.

${ }^{37}$ Российская Федерация не участвует.
} 
применении недобровольных психиатрических мер - госпитализации и лечения (ст.1). В этой связи в Рекомендациях содержатся детальные критерии и для недобровольного помещения в психиатрический стационар, и для недобровольного лечения (ст.17, 18), а также процедурные гарантии для принятия таких решений (ст.20), включая неотложные случаи (ст.21).

Однако по содержанию эти Рекомендации шире, чем ранее принятые. В них не только запрещается дискриминация и подтверждаются гражданские и политические права лиц с психическими расстройствами $($ ст. 3,4$)$ но и обращается внимание на деятельность по оказанию психиатрической помощи. Для этого в Рекомендации включены положения, относящиеся к профессиональным стандартам для работников служб психического здоровья (ст.11), общим принципам лечения психических расстройств (ст.12), особым ситуациям, возникающим при оказании психиатрической помощи (ст.27), а также некоторым видам медицинских вмешательств (ст. 28). Кроме того, в Рекомендациях для специальной защиты выделяется отдельная категория психиатрических пациентов, которые не способны дать согласие на госпитализацию, но в то же время против нее не возражают (ст.26).

Еще на стадии подготовки Rec(2004)10 специалисты отмечали, что « рекомендации являются полными и создаются с целью обеспечить минимальные стандарты помощи, особенно для тех, кто подвергается недобровольным процедурам, во всем государствах-членах ${ }^{38}$ Совета Европы. Их значение не только в том, что они более детально регламентируют применение недобровольных мер в психиатрической помощи, но и обращают внимание государств на «важность обеспечения необходимых ресурсов» для такой помощи и принятие мер к «дестигматизации психических расстройств» ${ }^{39}$.

В заключение надо отметить, что на сегодняшний день и на уровне $\mathrm{OOH}$, и в Совете Европы существует достаточно обширный набор международно-правовых инструментов, гарантирующих права лиц с психическими расстройствами. Они могут использоваться при подготовке или пересмотре национальных законов в сфере психического здоровья, а также практики их применения.

\section{Библиография:}

1. Броунли Я. Международное право: в 2-х кн. - М.: «Прогресс», 1977.

2. Гомиен Д. Путеводитель по Европейской конвенции о защите прав человека. - Страсбург: Совет Европы. 1994.

3. Ануфриева Л.П., Бекяшев Д.К., Бекяшев К.А. Международное публичное право: учеб. /Л.П. Ануфриева, Д.К. Бекяшев, К.А. Бекяшев [и др.]; отв. ред. К.А.Бекяшев. - М.: ТК Велби, Изд-во Проспект, 2004.

4. Нгуен Куок Динь, Дайе П., Пеле А. Международное публичное право: в 2-х т. - Киев: «Сфера», 2000.

5. Gostin L., Gable L. The Human Rights of Persons with Mental Disabilities: a Global Perspective on the Application of Human Rights Principles to Mental Health// Maryland Law Review. 2004. Vol.63:20. P. 20-121.

6. Kingdon D., Jones R., Lönnqvist J. Protection the human rights of people with mentsl disorder: new recommendations emerging from the Council of Europe// British Journal of Psychiatry. 2004. Vol.185. P. 277-279.

7. Lewis O. Protecting the Rights of People with Mental Disabilities: The European Convention on Human Rights//European Journal of Health Law. 2002. Number 9. P.293-320.

8. Wittchen H.U. et al. The size and burden of mental disorders and other disorders of the brain in Europe 2010 //European Neuropsychopharmacology (2011) 21. P.655-679. //www.elsevier.com/locate/euroneuro.

9. Zifcak S. The United Nation Principles for the Protection of People with Mental Illness: Applications and Limitations// Psychiatry, Psychology and Law. Vol.3. Number 1. April 1996. P.1-9.

\footnotetext{
${ }^{38}$ Kingdon D., Jones R., Lönnqvist J. Protection the human rights of people with mentsl disorder: new recommendations emerging from the Council of Europe// British Journal of Psychiatry. 2004. Vol.185. P. 279.

${ }^{39}$ Ibid.
} 


\section{References (transliteration):}

1. Brounli Ya. Mezhdunarodnoe pravo: v 2-kh kn. - M.: «Progress», 1977.

2. Gomien D. Putevoditel' po Evropeiskoi konventsii o zashchite prav cheloveka. - Strasburg: Sovet Evropy. 1994.

3. Anufrieva L.P., Bekyashev D.K., Bekyashev K.A. Mezhdunarodnoe publichnoe pravo: ucheb. /L.P. Anufrieva, D.K. Bekyashev, K.A. Bekyashev [i dr.]; otv. red. K.A.Bekyashev. - M.: TK Velbi, Izd-vo Prospekt, 2004.

4. Nguen Kuok Din', Daie P., Pele A. Mezhdunarodnoe publichnoe pravo: v 2-kh t. - Kiev: «Sfera», 2000.

5. Gostin L., Gable L. The Human Rights of Persons with Mental Disabilities: a Global Perspective on the Application of Human Rights Principles to Mental Health// Maryland Law Review. 2004. Vol.63:20. R. 20-121.

6. Kingdon D., Jones R., Lönnqvist J. Protection the human rights of people with mentsl disorder: new recommendations emerging from the Council of Europe// British Journal of Psychiatry. 2004. Vol.185. P. 277-279.

7. Lewis O. Protecting the Rights of People with Mental Disabilities: The European Convention on Human Rights//European Journal of Health Law. 2002. Number 9. P.293-320.

8. Wittchen H.U. et al. The size and burden of mental disorders and other disorders of the brain in Europe 2010 //European Neuropsychopharmacology (2011) 21. P.655-679. //www.elsevier.com/locate/euroneuro.

9. Zifcak S. The United Nation Principles for the Protection of People with Mental Illness: Applications and Limitations// Psychiatry, Psychology and Law. Vol.3. Number 1. April 1996. R.1-9. 